\title{
Macromolecule exchange in Cuscuta-host plant interactions
}

Gunjune Kim ${ }^{\mathrm{a}}$ and James H. Westwood ${ }^{\mathrm{a} *}$

${ }^{a}$ Department of Plant Pathology, Physiology and Weed Science, Virginia Tech, Latham Hall (0390), Blacksburg, VA 24061

*Corresponding author: westwood@vt.edu 1-540-231-7519.

\section{Abstract}

Cuscuta species (dodders) are parasitic plants that are able to grow on many different host plants and can be destructive to crops. The connections between Cuscuta and its hosts allow movement of not only water and small nutrients, but also macromolecules including mRNA, proteins and viruses. Recent studies show that RNAs move bidirectionally between hosts and parasites and involve a large number of different genes. Although the function of mobile mRNAs has not been demonstrated in this system, small RNAs are also transmitted and a silencing construct expressed in hosts is able to affect expression of the target gene in the parasite. High throughput sequencing of host-parasite associations has the potential to greatly accelerate understanding of this remarkable interaction. 


\section{Introduction}

Parasitic plants of the genus Cuscuta (dodders) are extraordinary examples of plant evolution in terms of their interactions with other plants. About 200 Cuscuta species are distributed throughout the world and they are destructive to trees, shrubs and cultivated crops such as tomato, cranberry, alfalfa, etc. [1,2]. They are members of the family Convolvulaceae and evolved from autotrophic ancestors, but specialized to live parasitically by connecting to host plants in order to extract water, nutrients, and metabolites. Cuscuta species are holoparasitic on their hosts and although some species synthesize chlorophyll, others have lost extensive portions of their plastic genomes so as to be functionally nonphotosynthetic [3]. The plants are unusual in many other ways as well. Shortly after attachment to a host the parasite root senesces and Cuscuta draws all subsequent water from the host. Cuscuta also appears to lack leaves, which are reduced to vestigial scales, and as a result the vegetative structure of the plant consists of stem, ranging in color from greenish to pale yellow or orange, depending on the species, which coils around their hosts and connects to host tissues via specialized organs termed haustoria.

Given their obligate dependence on the host, Cuscuta are highly attuned to finding and parasitizing their hosts. Cuscuta seeds germinate in the spring like other annual plants, but here the similarities end. The Cuscuta shoot is a thread-like stem that grows upward, rotating in a counterclockwise direction until contacting a vertical host stem. Location of the host is accomplished with sophisticated mechanisms including detection of light quality, with blue and far red wavelengths promoting coiling and haustoria formation [4]. Volatile chemical signals emitted by hosts and non-host plants also aid in host detection by attracting or repelling the parasite such that the odds of contacting a favored host species are improved [5]. Another essential signal is touch, and as the parasite encounters a host stem it coils around it and forms haustoria along the inner side of the coil (Figure 1). The haustoria penetrate the host to form vascular connections from which the parasite obtains all of its resources. The parasite shoot then grows, branching prolifically and forming new connections to create a network of stems connected to hosts, and potentially bridging several different host species simultaneously.

Various aspects of Cuscuta biology have been reviewed in recent years, including overall parasitic mechanisms [2,4], host resistance [6] and transfer of materials [7,8]. This review will focus on the most recent advances in understanding host-Cuscuta interactions with particular emphasis on haustorial transfer of macromolecules that may act in information exchange.

\section{Cuscuta-host connections: a unique system}


Perhaps the most unique aspect of the Cuscuta connection to its host is the open translocation of substances between the two organisms. In addition to small molecules such as water and photosynthates, Cuscuta takes up macromolecules including nucleic acids, and even pathogens such as viruses and phytoplasmas (Table 1). Although many aspects of this interaction have been studied, precise mechanisms regulating macromolecule transmission remain unclear.

The Cuscuta haustorium initiates in the parasite stem from cortical and epidermal cells that expand to form a lateral protuberance, variously termed the upper haustorium, adhesive disk or pseudohaustorium, which elongates toward the host stem and adheres by means of excreted pectinaceous "cement" material $[9,10]$. From this develops the lower haustorium, which invades the host and then gives rise to searching hyphae, specialized cells that elongate between and through host cells to reach the host vascular tissue (Figure 1D)[11]. The ability of searching hyphae to grow through host cells creates a situation in which host cell walls form in association with new parasite cell walls and are spanned by plasmodesmata (Figure 1F). These plasmodesmata represent clear points of symplastic connection between the species and offer a potential route for exchange of macromolecules. In addition, the searching hyphae connect to host vascular tissue, and those that contact host xylem differentiate into xylem cells, whereas those that contact host phloem differentiate into phloem-type cells with aspects of transfer cells (Figure 1G,H)[12]. The xylem connections form an open conduit between host and parasite, whereas the phloem connections between host and parasite involve membrane and cell wall barriers. Nevertheless, movement of labeled sugars, phloem-mobile dye and virus strongly indicate symplastic continuity [13].

\section{RNA trafficking in the host-Cuscuta interaction}

RNAs have roles beyond coding for protein, including acting at multiple levels to regulate gene expression. Within a single plant, mRNAs may move between cells to transmit information over short or long distances, and this may be a mechanism for coordinating growth and development $[14,15]$. The finding that hosts and Cuscuta exchange RNA raises the possibility that this type of communication can occur in an interspecies manner, such that mRNA movement is not even limited to the organism in which it was produced $[16,17]$.

The scope of RNA exchange between host and Cuscuta can be large and bidirectional. A study of Cuscuta pentagona growing on Arabidopsis estimated that about $1 \%$ of the RNAs in the parasite stem near the point of haustorial attachment to the host were of Arabidopsis origin, while in the reverse direction $0.6 \%$ of RNAs in the Arabidopsis stem were of Cuscuta origin $\left[18^{* *}\right]$. The diversity of genes represented among these mobile RNAs was high, as $44 \%(>9,000)$ of expressed host transcripts were detected as mobile 
into the parasite and $24 \%$ of expressed Cuscuta unigenes were detected in the host. A similar experiment using $C$. reflexa identified over 2,000 mobile transcripts from Arabidopsis [19** $]$. It is noteworthy that the magnitude of RNA movement depended on the host species used in the interaction (greater exchange with Arabidopsis vs. tomato hosts) and likely also depends on the Cuscuta species, experimental conditions, depth of sequencing, etc. $\left[18^{* *}, 19^{* *}\right]$. But together these studies indicate that substantial proportions of host and parasite transcriptomes are capable of intercellular mobility.

Mobility of such diverse transcripts raises the question of how RNA moves between the species and the extent to which this movement is regulated. Patterns of movement suggest that some regulation occurs, but no specific features of transcript form or function were correlated with mobility. One major predictor of mobility is simply the abundance of a transcript in the region of the haustorial connection, but this alone cannot account for mobility as evidenced by contrasting examples of highly expressed non-mobile and lowly expressed mobile transcripts $\left[18^{* *}, 19^{* *}\right]$. A study of mRNA movement across root-shoot graft junctions in Arabidopsis provides compelling evidence that transcript mobility is regulated by factors such as nutrient status and that transcripts may move in directional patterns (e.g. root to shoot and vice versa) and be targeted to specific organs $\left[19^{\star *}\right]$. With this in mind it is interesting to consider movement of Cuscuta transcripts into the host. Such flow against the predominant source-sink gradient is consistent with bidirectional transport in phloem. Cuscuta mRNAs moving into host cells would be advantageous for the parasite if they facilitate communication and colonization of host tissues.

The exact cellular route of RNA exchange is uncertain, but is consistent with parasite connections to host parenchyma and phloem (Figure $1 \mathrm{~F}$ and $\mathrm{H}$ ). In situ hybridizations of mRNAs moving from host to Cuscuta indicated that host mRNA transfer occurred between host parenchyma cells and searching hyphae of the parasite [17], ultimately translocating long distance in Cuscuta phloem $[17,20]$. No size cutoff for RNA transfer was identified for Cuscuta and its Arabidopsis or tomato hosts [18**], although the mass limit for protein movement was determined to be between 27 and $36 \mathrm{kDa}$ [21]. Under normal circumstances RNA movement between plant cells is thought to be mediated by RNA association with proteins that facilitate passage through plasmodesmata [22]. The exchange of RNA between hosts and Cuscuta appears to be closer to a "bulk flow" model of mobility, and it is possible that the pathogenic nature of Cuscuta parasitism creates abnormally open connections with hosts.

The fate of host transcripts in the parasite is not clear. Possibilities include translation to protein in the recipient organism, processing into silencing signals that can affect gene expression, or simply degradation into component nucleotides. A tomato transcript 
moving into Cuscuta largely disappeared within $8 \mathrm{hrs}$ of the parasite stem being severed from the host [20]. While evidence of mRNA function is currently lacking, a mobile protein has shown evidence of function. The herbicide metabolizing enzyme phosphinothricin acetyl transferase (PAT) was detected in Cuscuta growing on PAT expressing transgenic soybean and appeared to protect the parasite against glufosinate injury [23*].

\section{Silencing RNA}

The best evidence that mobile RNA has an effect on gene expression of the recipient plant comes from trans-specific gene silencing experiments. This approach uses a gene sequence specific to the parasite and expresses it in the host in a hairpin construct to generate a mobile silencing signal that affects the target gene in the parasite. The clearest examples of this to date in parasitic plants come from Triphysaria versicolor, a root parasite in the family Orobanchaceae, in which siRNAs expressed in the host reduce expression of a gene expressed in the parasite [24,25*]. For Cuscuta this technique was employed to silence SHOOT MERISTEMLESS-Like, a gene encoding a parasite transcription factor important in shoot development, resulting in malformed haustorial searching hyphae and reduced parasite vigor [26*]. This approach has potential to be a breakthrough technology in the control of parasitic weeds, at least for those species that absorb the siRNA signals from their hosts [27-29]. As a research tool it is currently the best approach for gene function studies for Cuscuta, which has not been successfully transformed and regenerated. The significance of small RNA movement between host and parasite species is not known. However, to the extent that small RNAs are an important component of plant genome regulation [30], it is likely that the parasite would have a mechanism for using both self and non-self RNAs. An intriguing possibility is that Cuscuta siRNAs move into the host and act as effectors to manipulate host defenses similar to the way the fungus Botrytis cinerea suppresses host immunity [31].

\section{Parasite transcriptomes aid in understanding host interactions}

Transcriptome sequencing using high throughput technology has great potential for studying host-parasite interactions. Given that the parasites and their hosts are different species and often phylogenetically distant from each other, it is possible to sequence RNA from intermixed tissues at the haustoria-host connection and then separate the two transcriptomes based on prior knowledge of host genomic sequences. As more parasite transcriptomes and genomes become available this process will increase in ease and accuracy. This approach is being used to identify genes that are important in haustorial development and provide insight into parasite-host interactions. 
Transcriptional analyses of Cuscuta at various stages of development identified genes associated with the haustorium of Cuscuta [32**]. Genes specifically induced during haustorial stages include those involved in cell wall modification (e.g., pectin methylesterase, cellulase, and expansins), which is a recurring theme in parasitism $\left[18^{* *}, 33,34\right]$ and consistent with the needs of the parasite to deform host cells and expand its own cells during haustorial invasion. Other genes induced include those related to pathogen or stress response (indicating a role for plant defense as a component of parasitism) and increased transporter activity (consistent with the uptake of nutrients). Shoot tip regions of $C$. pentagona and $C$. suaveloens were enriched in transcripts encoding proteins involved in biological adhesion, which may aid in forming connections to new hosts [35]. Considering the broad host range of Cuscuta, it would be interesting to know whether haustorial connections differ depending on the host contacted. This is true for Triphysaria haustoria, which induced expression of specific expansin genes appropriately depending on whether it was parasitizing monocot or dicot hosts [33].

\section{Horizontal gene transfer (HGT)}

HGT comprises another type of macromolecule exchange and one that is especially prevalent between parasitic plants and their hosts [36,37] (See also the review in this issue [38]). Although no fitness benefit has been proven for HGT-acquired genes, Cuscuta and Phelipanche species both obtained an apparently functional albumin 1 gene from legumes [39] and strictosidine synthase-like gene from Brassicaceae [40], suggesting that these HGT events provide competitive advantages. Considering the constant exchange of mRNA in Cuscuta-host interactions described above, it is interesting that examples of RNA-mediated HGT have not been reported. The closest example is a nuclear encoded gene that appears to have moved from Sorghum into Striga hermonthica and contained potential remnants of a poly-A tail [41]. Rather, the mechanism of HGT between plants is likely mediated through genomic DNA transfer $[37,42,43]$. The physical contact between host and parasite may lead to the same type of cell-cell contact that has been reported in DNA or organelle exchange in plant graft interactions $[44,45]$. No systemic movement of DNA has been documented in parasitehost interactions.

\section{Conclusions}

Cuscuta has many characteristics of an ideal subject for studying plant-plant interactions. Starting as a seedling it exhibits sophisticated mechanisms for locating a host, integrating into host tissues, and extracting host nutrients. The ability to establish symplastic connections with a wide range of host species such that it can exchange RNAs and proteins is an especially intriguing aspect of the interaction (Box 1). Given that Cuscuta has evolved to mix its RNAs with those of a host, it is reasonable to 
assume that it also has mechanisms to deal with this added complexity. Perhaps Cuscuta can distinguish self from non-self RNAs, using each type of transcript for a specific purpose. Alternatively, Cuscuta may have evolved to function without regard for transcript source, processing them all equally. Regardless which of these possibilities is closer to the truth, Cuscuta will provide valuable insights into mobile RNAs and plant interactions.

\section{Acknowledgements}

This work was supported by funding from NSF IOS-0843372 and NSF IOS-1238057. Additional support to JHW was provided by National Institute of Food and Agriculture project no. 135997. 
Table 1. Summary of the types of molecules and organisms that move between hosts and Cuscuta.

\begin{tabular}{|l|l|l|l|l|}
\hline Category & Examples & $\begin{array}{l}\text { Cuscuta } \\
\text { species }\end{array}$ & Host species & Reference \\
\hline Water & C. reflexa; C. & $\begin{array}{l}\text { Coleus; } \\
\text { Tithonia } \\
\text { tubiformis }\end{array}$ & {$[46,47]$} \\
\hline Metabolite & Sugars, amino acids & C. reflexa & Lupin & {$[48]$} \\
\hline Herbicide & $\begin{array}{l}\text { Glyphosate and } \\
\text { ALS inhibitors }\end{array}$ & C. campestris & & {$[49]$} \\
\hline Protein & $\begin{array}{l}\text { Green fluorescent } \\
\text { protein; } \\
\text { Phosphinothricin } \\
\text { acetyl transferase }\end{array}$ & $\begin{array}{l}\text { C. reflexa; } \\
\text { C. pentagona }\end{array}$ & $\begin{array}{l}\text { Tobacco; } \\
\text { Soybean }\end{array}$ & {$\left[23^{*}, 50\right]$} \\
\hline mRNA & $\begin{array}{l}\text { Many } \\
\text { C. pentagona } \\
\text { C. reflexa }\end{array}$ & $\begin{array}{l}\text { Tomato, } \\
\text { Arabidopsis, } \\
\text { Alfalfa, } \\
\text { Pumpkin }\end{array}$ & {$\left[16,17,18^{* *}, 19^{\star *}\right]$} \\
\hline siRNA & $\begin{array}{l}\text { Shoot Meristemless } \\
- \text {-like }(\text { STM })\end{array}$ & C. pentagona & Tobacco & {$[26]$} \\
\hline DNA & atp1, atp6, matR; & C. gronovii & Plantago & {$[42]$} \\
\hline Viroid & HSVd & C. subinclusa & Cucumber & {$[31,51]$} \\
\hline Virus & PVYN & C. reflexa & Tobacco & {$[13]$} \\
\hline Phytoplasma & Yellows disease & C. campestris & Periwinkle & {$[52]$} \\
\hline
\end{tabular}

Box 1. Outstanding questions in Cuscuta-host interactions.

1. What mechanisms govern the movement of mRNA between hosts and Cuscuta?

2. Dos Cuscuta exhibit host-specific RNA exchange when parasitizing different hosts?

3. What is the fate of host mobile RNAs in the recipient organism: Translation, gene regulation, or degradation?

4. Are non-self RNAs identified and processed differently from self RNAs?

5. Are Cuscuta RNAs important in haustorial penetration and function in hosts?

6. Does RNA movement via Cuscuta contribute to horizontal gene transfer in plants?

Figure legend 
Figure 1. Cuscuta haustorial connections with its host. (A) Overview of Cuscuta (yellow stem) growing on an Arabidopsis thaliana host plant. (B) Close-up view of Cuscuta coiled around host stem tissue. Swollen areas of Cuscuta stem are points of haustorial development. (C) Cross-section of a coil showing Cuscuta haustoria penetrating the host stem (vascular bundles indicated by blue (phloem) and red (xylem). (D) Magnified view of an invading haustorium showing intrusively growing searching hyphae. (E) Magnified view of a mature haustorium showing the connection of parasite cells with host vascular tissues. (F) Further magnification of the chimeric cell wall between searching hyphae cell and host parenchyma cell, joined by interspecific plasmodesmata. (G) Further magnification of Cuscuta connection with the host xylem cells (red lines). (H) Further magnification of Cuscuta connection with the host phloem cells (blue lines). Although the exact path of mRNA exchange is unclear, evidence points to involvement of both plasmodesmatal $(F)$ and phloem $(H)$ connections. [Illustrations based on 11,12,21,53,54].

\section{References and recommended reading}

Papers of particular interest, published within the period of review, have been highlighted as:

* of special interest

** of outstanding interest

1. Dawson J, Musselman L, Wolswinkel P, Dörr I: Biology and control of Cuscuta. Rev Weed Sci 1994, 6:265-317.

2. Costea M, Tardif FJ: The biology of Canadian weeds. 133. Cuscuta campestris Yuncker, C. gronovii Willd. ex Schult., C. umbrosa Beyr. ex Hook., C. epithymum (L.) L. and C. epilinum Weihe. Can J Plant Sci 2006, 86:293-316.

3. Braukmann T, Kuzmina M, Stefanovic S: Plastid genome evolution across the genus Cuscuta (Convolvulaceae): two clades within subgenus Grammica exhibit extensive gene loss. J Exp Bot 2013, 64:977-989.

4. Furuhashi $\mathrm{T}$, Furuhashi $\mathrm{K}$, Weckwerth $\mathrm{W}$ : The parasitic mechanism of the holostemparasitic plant Cuscuta. J Plant Interact 2011, 6:207-219.

5. Runyon JB, Mescher MC, De Moraes CM: Volatile chemical cues guide host location and host selection by parasitic plants. Science 2006, 313:1964-1967.

6. Kaiser B, Fürst UB, Vogg G, Albert M: Parasitic plants of the genus Cuscuta and their interaction with susceptible and resistant host plants. Front Plant Sci 2015, 6:45.

7. LeBlanc M, Kim G, Westwood JH: RNA trafficking in parasitic plant systems. Front Plant Sci 2012, 3.

8. Smith JD, Mescher MC, De Moraes CM: Implications of bioactive solute transfer from hosts to parasitic plants. Curr Opin Plant Biol 2013, 16:464-472.

9. Vaughn KC: Attachment of the parasitic weed dodder to the host. Protoplasma 2002, 219:227-237. 
10. Hong L, Shen H, Chen H, Li L, Hu X, Xu X, Ye W, Wang Z: The morphology and anatomy of the haustoria of the holoparasitic angiosperm Cuscuta campestris. Pakistan J Bot 2011, 43:18531859.

11. Vaughn KC: Dodder hyphae invade the host: a structural and immunocytochemical characterization. Protoplasma 2003, 220:189-200.

12. Vaughn KC: Conversion of the searching hyphae of dodder into xylic and phloic hyphae: $A$ cytochemical and immunocytochemical investigation. Int J Plant Sci 2006, 167:1099-1114.

13. Birschwilks M, Haupt S, Hofius D, Neumann S: Transfer of phloem-mobile substances from the host plants to the holoparasite Cuscuta sp. J Exper Bot 2006, 57:911-921.

14. Spiegelman Z, Golan G, Wolf S: Don't kill the messenger: Long-distance trafficking of mRNA molecules. Plant Sci 2013, 213:1-8.

15. Turnbull CGN, Lopez-Cobollo RM: Heavy traffic in the fast lane: long-distance signalling by macromolecules. New Phytol 2013, 198:33-51.

16. Roney JK, Khatibi PA, Westwood JH: Cross-species translocation of mRNA from host plants into the parasitic plant dodder. Plant Physiol 2007, 143:1037-1043.

17. David-Schwartz R, Runo S, Townsley B, Machuka J, Sinha N: Long-distance transport of mRNA via parenchyma cells and phloem across the host-parasite junction in Cuscuta. New Phytol 2008, 179:1133-1141.

18. Kim G, LeBlanc ML, Wafula EK, Depamphilis CW, Westwood JH: Genomic-scale exchange of mRNA between a parasitic plant and its hosts. Science 2014, 345:808-811.

** Demonstrates bidirectional movement of mRNAs in Cuscuta-host interactions and that mobile transcripts are broadly representative of gene expression in the region of haustorium connection. The approach used transcriptome analyses of $C$. pentagona growing in association with Arabidopsis or tomato hosts.

19. Thieme CJ, Rojas-Triana M, Stecyk E, Schudoma C, Zhang W, Yang L, Miñambres M, Walther D, Schulze WX, Paz-Ares J, et al.: Endogenous Arabidopsis messenger RNAs transported to distant tissues. Nature Plants 2015, 1.

** Demonstrates the movement of RNA from Arabidopsis into C. reflexa. Beyond this, it employs an elegant system of grafting distinct ecotypes of Arabidopsis in order to differentiate RNA movement between roots and shoots, thereby revealing features of RNA trafficking in the phloem. Highlights include evidence of directional transport of specific RNAs and that environmental conditions such as nutrient stress can alter transcript mobility.

20. LeBlanc M, Kim G, Patel B, Stromberg V, Westwood J: Quantification of tomato and Arabidopsis mobile RNAs trafficking into the parasitic plant Cuscuta pentagona. New Phytol 2013, 200:1225-1233.

21. Birschwilks M, Sauer N, Scheel D, Neumann S: Arabidopsis thaliana is a susceptible host plant for the holoparasite Cuscuta spec. Planta 2007, 226:1231-1241.

22. Xoconostle-Cázares B, Xiang Y, Ruiz-Medrano R, Wang H-L, Monzer J, Yoo B-C, McFarland KC, Franceschi VR, Lucas WJ: Plant paralog to viral movement protein that potentiates transport of mRNA into the phloem. Science 1999, 283:94-98.

23. Jiang L, Qu F, Li Z, Doohan D: Inter-species protein trafficking endows dodder (Cuscuta pentagona) with a host-specific herbicide-tolerant trait. New Phytol 2013, 198:1017-1022.

* Reports that Cuscuta acquires transient resistance to glufosinate through transfer of the glufosinate-detoxifying enzyme phosphinothricin acetyl transferase (PAT) from transgenic hosts expressing the PAT gene. The PAT protein was detected in the parasite, while no PAT mRNA was detected, indicating that the protein is obtained directly from the host.

24. Tomilov AA, Tomilova NB, Wroblewski T, Michelmore R, Yoder JI: Trans-specific gene silencing between host and parasitic plants. Plant J 2008, 56:389-397. 
25. Bandaranayake PC, Yoder JI: Trans-specific gene silencing of acetyl-CoA carboxylase in a rootparasitic plant. Mol Plant Microbe Interact 2013, 26:575-584.

* This study confirms pioneering previous work that gene silencing functions in an angiosperm parasite-host interaction and extends it by showing that a host-expressed RNAi construct specific to a Triphysaria versicolor acetyl-CoA carboxylase (ACCase) gene was debilitating to the parasite. The ACCase enyzme is a target of herbicides, so this work provides proof-of-concept for engineering parasite resistant host crops.

26. Alakonya A, Kumar R, Koenig D, Kimura S, Townsley B, Runo S, Garces HM, Kang J, Yanez A, DavidSchwartz R, et al.: Interspecific RNA interference of SHOOT MERISTEMLESS-like disrupts Cuscuta pentagona plant parasitism. Plant Cell 2012, 24:3153-3166.

* Shows how trans-specific gene silencing can be used to study gene function of obligate parasitic plants.

27. Yoder JI, Gunathilake $P, W u$ B, Tomilova N, Tomilov AA: Engineering host resistance against parasitic weeds with RNA interference. Pest Manag Sci 2009, 65:460-466.

28. Runo S, Alakonya A, Machuka J, Sinha N: RNA interference as a resistance mechanism against crop parasites in Africa: a 'Trojan horse' approach. Pest Manag Sci 2011, 67:129-136.

29. Aly R, Cholakh H, Joel DM, Leibman D, Steinitz B, Zelcer A, Naglis A, Yarden O, Gal-On A: Gene silencing of mannose 6-phosphate reductase in the parasitic weed Orobanche aegyptiaca through the production of homologous dsRNA sequences in the host plant. Plant Biotechnol J 2009, 7:487-498.

30. Molnar A, Melnyk CW, Bassett A, Hardcastle TJ, Dunn R, Baulcombe DC: Small Silencing RNAs in Plants Are Mobile and Direct Epigenetic Modification in Recipient Cells. Science 2010, 328:872875.

31. Weiberg A, Wang M, Lin F-M, Zhao H, Zhang Z, Kaloshian I, Huang H-D, Jin H: Fungal small RNAs suppress plant immunity by hijacking host RNA interference pathways. Science 2013, 342:118123.

32. Ranjan A, Ichihashi Y, Farhi M, Zumstein K, Townsley B, David-Schwartz R, Sinha NR: De novo assembly and characterization of the transcriptome of the parasitic weed dodder identifies genes associated with plant parasitism. Plant Physiol 2014, 166:1186-1199.

** Provides detailed transcriptional analyses of Cuscuta pentagona developmental stages and identifies classes of genes associated with the prehaustorium and haustorium.

33. Honaas LA, Wafula EK, Yang Z, Der JP, Wickett NJ, Altman NS, Taylor CG, Yoder JI, Timko MP, Westwood JH, et al.: Functional genomics of a generalist parasitic plant: laser microdissection of host-parasite interface reveals host-specific patterns of parasite gene expression. BMC Plant Biol 2013, 13:9.

34. Yang Z, Wafula EK, Honaas LA, Zhang H, Das M, Fernandez-Aparicio M, Huang K, Bandaranayake PC, Wu B, Der JP, et al.: Comparative transcriptome analyses reveal core parasitism genes and suggest gene duplication and repurposing as sources of structural novelty. Mol Biol Evol 2014.

35. Jiang LJ, Wijeratnen AJ, Wijeratne S, Frage M, Meulia T, Doohan D, Li ZH, Qu F: Profiling mRNAs of two Cuscuta species reveals possible candidate transcripts shared by parasitic plants. Plos One 2013, 8.

36. Barkman TJ, McNeal JR, Lim S-H, Coat G, Croom HB, Young ND, dePamphilis CW: Mitochondrial DNA suggests at least 11 origins of parasitism in angiosperms and reveals genomic chimerism in parasitic plants. BMC Evol Biol 2007, 7:248.

37. Xi Z, Bradley RK, Wurdack KJ, Wong K, Sugumaran M, Bomblies K, Rest JS, Davis CC: Horizontal transfer of expressed genes in a parasitic flowering plant. BMC genomics 2012, 13:227. 
38. Davies C, Xi T: Horizontal Gene Transfer between plants and parasitic plant. Curr Op Plant Biol 2015, 26:(This issue).

39. Zhang Y, Fernandez-Aparicio M, Wafula EK, Das M, Jiao Y, Wickett NJ, Honaas LA, Ralph PE, Wojciechowski MF, Timko MP, et al.: Evolution of a horizontally acquired legume gene, albumin 1, in the parasitic plant Phelipanche aegyptiaca and related species. BMC evolutionary biology 2013, 13:48.

40. Zhang D, Qi J, Yue J, Huang J, Sun T, Li S, Wen JF, Hettenhausen C, Wu J, Wang L, et al.: Root parasitic plant Orobanche aegyptiaca and shoot parasitic plant Cuscuta australis obtained Brassicaceae-specific strictosidine synthase-like genes by horizontal gene transfer. BMC plant biology 2014, 14:19.

41. Yoshida S, Maruyama S, Nozaki H, Shirasu K: Horizontal gene transfer by the parasitic plant Striga hermonthica. Science 2010, 328:1128.

42. Mower J, Stefanovic S, Hao W, Gummow J, Jain K, Ahmed D, Palmer J: Horizontal acquisition of multiple mitochondrial genes from a parasitic plant followed by gene conversion with host mitochondrial genes. BMC Biology 2010, 8:150.

43. Gao C, Ren X, Mason A, Liu H, Xiao M, Li J, Fu D: Horizontal gene transfer in plants. Funct Integr Genomics 2014, 14:23-29.

44. Stegemann S, Bock R: Exchange of genetic material between cells in plant tissue grafts. Science 2009, 324:649-651.

45. Stegemann S, Keuthe M, Greiner S, Bock R: Horizontal transfer of chloroplast genomes between plant species. Proc Natl Acad Sci USA 2012, 109:2434-2438.

46. Jeschke WD, Baig A, Hilpert A: Sink-stimulated photosynthesis, increased transpiration and increased demand-dependent stimulation of nitrate uptake: Nitrogen and carbon relations in the parasitic association Cuscuta reflexa Coleus blumei. J Exp Bot 1997, 48:915-925.

47. Clayson C, García-Ruiz I, Costea M: Diversity, evolution, and function of stomata bearing structures in Cuscuta (dodders, Convolvulaceae): From extrafloral nectar secretion to transpiration in arid conditions. Perspec Plant Ecol Evol System 2014.

48. Hibberd JM, Jeschke WD: Solute flux into parasitic plants. J Exp Bot 2001, 52:2043-2049.

49. Nadler-Hassar T, Rubin B: Natural tolerance of Cuscuta campestris to herbicides inhibiting amino acid biosynthesis. Weed Res 2003, 43:341-347.

50. Haupt S, Oparka KJ, Sauer N, Neumann S: Macromolecular trafficking between Nicotiana tabacum and the holoparasite Cuscuta reflexa. J Exp Bot 2001, 52:173-177.

51. van Dorst HJM, Peters D: Some biological observations on pale fruit, a viroid-incited disease of cucumber. Eur. J. Plant Pathol. 1974, 80:85-96.

52. Pribylova J, Spak J: Dodder transmission of phytoplasmas. Methods Mol Biol 2013, 938:41 - 46.

53. Lee KB: Structure and development of the upper haustorium in the parasitic flowering plant Cuscuta japonica (Convolvulaceae). Am. J. Bot. 2007, 94:737-745.

54. Farah A, Ibrahim S: Anatomical Studies on Compatibility and Incompatibility of Some Solanaceous Plant Species to Field Dodder (Cuscuta campestris Yuncker). Am J Plant Sci 2014, 5:2426-2430. 
Figure

Figure 1

A

B

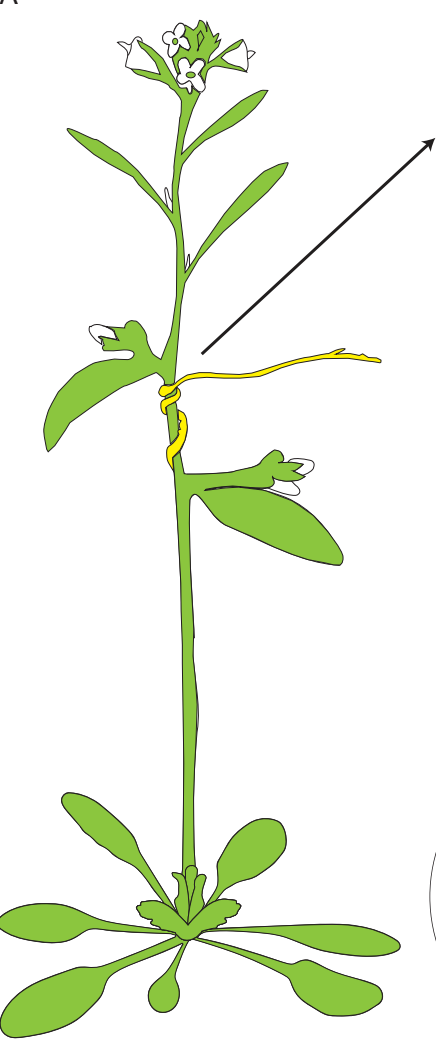

r

C

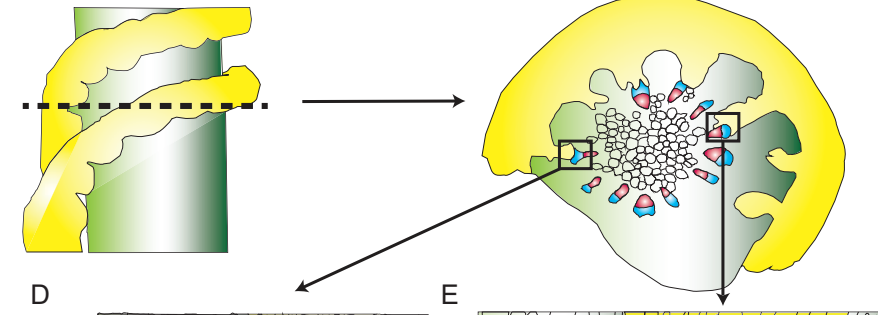

D

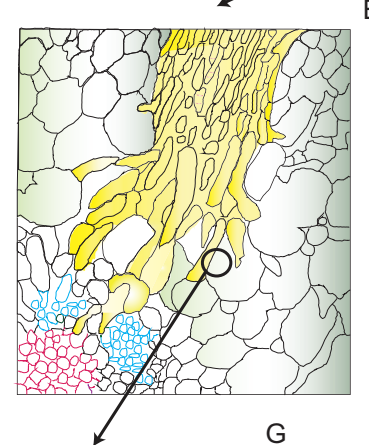

E

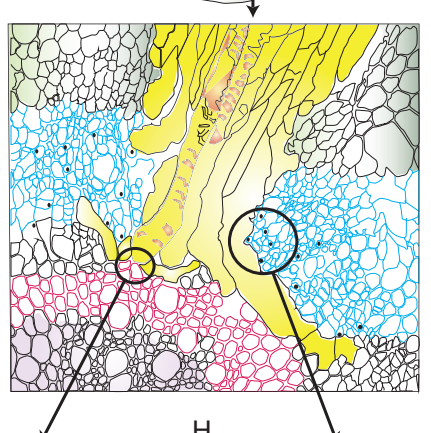

F

G
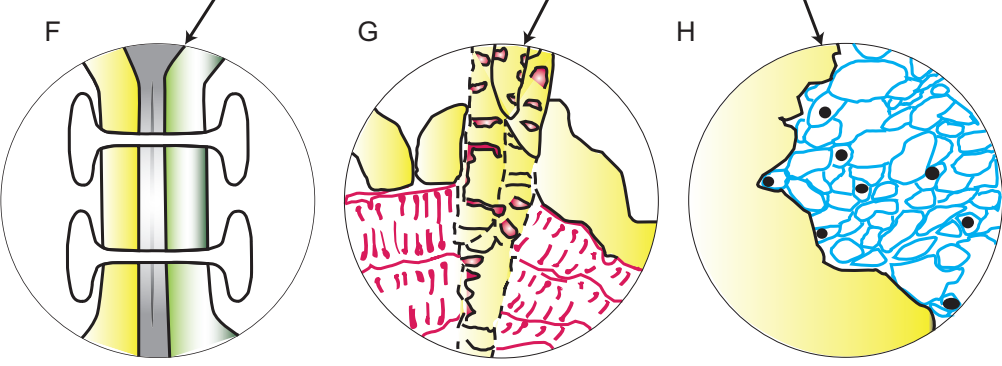